with a raised CRP. The DAPSA measures which do not include an enthesitis measure show more patients with an active enthesitis.

There was a limited consequence on QoL measures when residual disease activity was allowed in certain domains in these remission states. In those patients with active enthesitis or skin disease, no differences were found on PROs on quality of life and functionality. The presence of active skin disease with a PASI>2 (present in 20/110 pts achieving DAPSA) was reflected by an impact on DLQI $(2,85(S D 2,9)$ v.s. $1(2,3) p=0.003)$. This effect was not seen when the cutoff of for $\mathrm{PASI}>1$ was used.

\begin{tabular}{|c|c|c|c|c|c|}
\hline & cDAPSA $(n=113)$ & DAPSA $(n=107)$ & VLDA $(n=56)$ & PASDASNR $(\mathrm{n}=37$ \\
\hline \multicolumn{2}{|c|}{ PASDAS mean (SD) } & $2,16(0,52)$ & $2,13(0,49)$ & $1,97(0,42)$ & $1,6(0,20)$ \\
\hline \multirow{3}{*}{ SJC } & 0 & $101(89 \%)$ & $96(90 \%)$ & $53(95 \%)$ & $33(89 \%)$ \\
\hline & 1 & 10 & 10 & 3 & 1 \\
\hline & 2 & & & 0 & \\
\hline \multirow[t]{4}{*}{ TJC } & 0 & $93(82 \%)$ & $89(83 \%)$ & $51(91 \%)$ & $28(75 \%)$ \\
\hline & 1 & 11 & 11 & 5 & 2 \\
\hline & 2 & 7 & 5 & 0 & 4 \\
\hline & $3+$ & 2 & 2 & 0 & 3 \\
\hline \multirow[t]{3}{*}{ LEI } & 0 & $108(96 \%)$ & $102(96 \%)$ & $56(100 \%)$ & $37(100 \%)$ \\
\hline & 1 & 1 & 1 & 0 & 0 \\
\hline & $2+$ & 4 & 4 & 0 & 0 \\
\hline \multirow{2}{*}{ PASI score } & $0-1$ & $79(70 \%)$ & $74(69 \%)$ & $56(100 \%)$ & $32(86 \%)$ \\
\hline & $>1$ & 34 & 33 & 0 & 5 \\
\hline \multicolumn{2}{|c|}{$\mathrm{CRP}>5 \mathrm{mg} / \mathrm{dl}$} & $11(10 \%)$ & $8(7,5 \%)$ & $5(9 \%)$ & $1(3 \%)$ \\
\hline
\end{tabular}

Conclusions: This comparison of the different remission targets shows that VLDA presented as the most stringent target. Inclusion of laboratory markers seems not to be a necessity although the exclusion of a skin domain might result in a negligence of skin disease in some patients despite an impact on their QoL.

Disclosure of Interest: L. Van Mens: None declared, A. van Kuijk Grant/research support from: UCB, Pfizer, MSD, Janssen, Consultant for: Novartis, Celgene, D. Baeten Grant/research support from: Pfizer, MSD, AbbVie, UCB, Novartis, Janssen, Boehringer Ingelheim. This cohort was funded by an unrestricted grant from Pfizer to DB, Consultant for: Pfizer, MSD, AbbVie, UCB, Novartis, Janssen, Boehringer Ingelheim, Eli Lilly, Roche, BMS, Glenmark, Employee of: UCB, L. Coates: None declared

DOI: 10.1136/annrheumdis-2017-eular.2926

\section{SAT0465 AN INTEGRATED SAFETY DATA ANALYSIS ACROSS ALL PHASE II AND PHASE III CLINICAL PROGRAMS FOR USTEKINUMAB IN PSORIATIC ARTHRITIS, CROHN'S DISEASE, AND PSORIASIS}

L.S. Gensler ${ }^{1}$, E. Hsia ${ }^{2}$, C. Gasink ${ }^{2}$, B. Randazzo ${ }^{3}$, D. Parenti ${ }^{4}$, S. Fakharzadeh ${ }^{4}$, L.-L. Gao ${ }^{3}$ S.D. Chakravarty ${ }^{5}{ }^{1}$ University of California, San Francisco, San Francisco; ${ }^{2}$ Janssen Research \& Development, LLC/University of Pennsylvania, Spring House/Philadelphia; ${ }^{3}$ Janssen Research \& Development, LLC, Spring House; ${ }^{4}$ Janssen Scientific Affairs, LLC, Horsham; ${ }^{5}$ Janssen Scientific Affairs, LLC/Drexel University College of Medicine, Horsham/Philadelphia, United States

Objectives: Therapeutic decisions are based on efficacy, but clinicians need to consider medication safety in this process. Here, we report ustekinumab (UST) integrated safety data in patients (pts) with psoriatic arthritis (PsA), Crohn's disease (CD), and psoriasis (PsO). We also compare a subset of PsA pts with \& without baseline methotrexate (MTX).

Methods: Integrated safety data from $3 \mathrm{PsA}, 5 \mathrm{CD}$, \& 4 PsO trials were analyzed. PsA studies included the Ph2 trial [CNTO743T10] \& the $2 \mathrm{Ph} 3$ trials (PSUMMIT 1 \& 2) with 222,615 \& 312 pts exposed to UST, respectively. The percentage of pts in the Ph2 study that received MTX was $20.5 \%$. No concomitant DMARDs with the exception of MTX (approximately $50 \%$ of pts in each study) were permitted in the $2 \mathrm{Ph} 3$ studies. In the $5 \mathrm{CD}$ trials (Ph2/3Ph3) 1749 pts were exposed to UST. In the $3 \mathrm{Ph} 3 \mathrm{CD}$ trials, pts received one dose of UST $130 \mathrm{mg}$ or $\sim 6 \mathrm{mg} / \mathrm{kg}$ IV at induction (UNITI-1 \& UNITI-2), then 8 weeks later, entered the maintenance phase (IM UNITI) and received UST 90mg SC q8w or q12w for 44 weeks. The percentage of pts on background MTX in UNITI- 1 was $9.2 \%$ \& in UNITI-2, $4.8 \%$. In the $\mathrm{PsO}$ studies (1Ph2/3Ph3), a total of $3117 \mathrm{pts}$ received UST $45 \mathrm{mg}$ or $90 \mathrm{mg}$ SC; no concomitant DMARD therapy (including MTX) was permitted. The PsO studies were completed through 5-years of follow-up. All pts who received at least 1 dose of UST are included in this analysis. Safety events are reported in events per 100 -pt years. $95 \% \mathrm{Cl}$ for events per $100 \mathrm{PY}$ were estimated.

Results: Through 1 year of follow-up, a total of 1018 PsA pts were treated with UST, of which 465 were co-treated with MTX. Of the 1749 CD pts treated with UST, 139 received MTX. Discontinuation rates of UST due to adverse events (AEs) were comparable across disease states irrespective of MTX use (Table). $\mathrm{AE}$ rates $(95 \% \mathrm{Cls}$ for events/100 PY) were noted to be comparable in the UST vs PBO groups for all diseases pooled irrespective of MTX use-UST (420.39, $432.45)$ vs PBO $(534.80,570.44)$. Serious adverse event rates (SAEs) were also comparable in the UST vs PBO groups for all diseases pooled-UST $(14.25,16.56)$ vs PBO $(24.05,32.18)$. Infections and Serious infections (SIs) had numerically lower event rates in UST vs. PBO groups for all diseases pooled-UST (122.16, $128.72)$ vs PBO $(120.94,138.27)$ and UST $(2.10,3.05)$ vs PBO $(2.76,6.00)$, respectively (Table). Major adverse cardiovascular events (MACE) did not appear

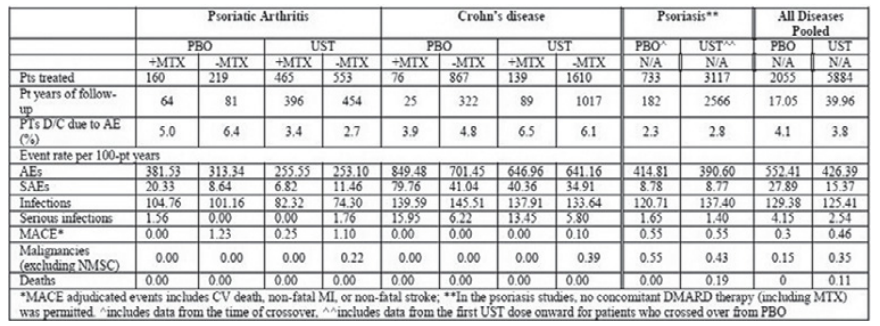

to significantly differ in both PBO \& UST pts in PsA, PsO and CD. Event rates of malignancy (excluding non-melanoma skin cancer) were comparable across all disease states. No deaths in PSA or CD were reported.

Conclusions: UST demonstrates a favorable safety profile in an integrated safety data analysis across the PsA, CD, \& PsO phase $2 \& 3$ clinical trials. The use of UST in PSA appears to be safe \& well-tolerated, with fewer event rates of SAEs \& SIs noted vs PBO. Despite higher overall rates of SAEs \& Sls observed in CD pts, the data do not suggest an influence of UST on either.

Disclosure of Interest: L. Gensler Grant/research support from: Janssen Scientific Affairs, LLC, E. Hsia Employee of: Janssen Research \& Development, LLC C. Gasink Employee of: Janssen Research \& Development, LLC, B. Randazzo Employee of: Janssen Research \& Development, LLC, D. Parenti Employee of: Janssen Scientific Affairs, LLC, S. Fakharzadeh Employee of: Janssen Scientific Affairs, LLC, L.-L. Gao Employee of: Janssen Research \& Development, LLC, S. Chakravarty Employee of: Janssen Scientific Affairs, LLC

DOI: 10.1136/annrheumdis-2017-eular.1116

\section{SAT0466 PREGNANCY IN WOMEN WITH PSORIATIC ARTHRITIS: PREGNANCY OUTCOMES AND CHANGES IN DISEASE ACTIVITY}

M.E.B. Clowse, G. McDaniel, A.M. Eudy. Rheumatology, Duke University Medical Center, Durham, United States

Background: Very little has been published about psoriatic arthritis (PsA) in pregnancy, and it remains unknown whether pregnancy outcomes are impacted by this disease or whether disease activity is changed by pregnancy or delivery. Objectives: To discover the rate of pregnancy complications for women with psoriatic arthritis, and to determine whether psoriasis and the associated arthritis change during and following pregnancy.

Methods: A retrospective survey was completed by 40 women aged 20-50 years with psoriatic arthritis managed at a university center. Each survey collected information about infertility, pregnancy outcomes and complications, as well as patient-reported assessments of changes in both skin and joint disease activity at the onset of pregnancy, over the course of the pregnancy, and in the months following pregnancy. Simple statistics were used to compare outcomes before and after the diagnosis of PsA.

Results: The survey was completed by 40 women with PsA. The majority (93\%) were white, non-Hispanic with a high level of education $(40 \%$ completed college and another $30 \%$ either started or finished a graduate degree); $62.5 \%$ were married. The average age at the time of the study was 37.4 (SD 7.9) years and age at PsA diagnosis was 30.9 (8.4) years.

Twenty-five women reported they had ever tried to become pregnant, and of those, 9 had been unable to become pregnant after 12 months of trying or had been diagnosed with infertility by a physician (36\%). The reasons for infertility or inability to become pregnant included polycystic ovarian syndrome $(44 \%)$, problem with ovulation $(11 \%)$, problem with uterus $(11 \%)$, elevated prolactin $(11 \%)$, infection in pelvic area $(11 \%)$, and/or cervical problems $(30 \%)$. Infertility was unexplained in $33 \%$.

There were 70 pregnancies to 26 patients, with 37 pregnancies occurring after the diagnosis of PsA (see table). Pregnancy outcomes following PsA diagnosis were worse than those prior to PsA diagnosis, particularly the rate of pregnancy loss $(32 \%$ compared to $12 \% ; p=0.05)$ and preterm birth $(48 \%$ compared to $21 \% ; p=0.02$ ). Only $24 \%$ of patients took psoriasis or arthritis medications during pregnancy. The most commonly used medications during pregnancy were TNF inhibitors (16\%), corticosteroids ( $8 \%)$, and DMARDs $(5 \%)$.

The large majority of patients had minimal arthritis and psoriasis during pregnancy.

\begin{tabular}{|c|c|cc|}
\hline Table. Pregnancy outcomes before and after psoriatic arthritis diagnosis. \\
\hline & Overall & $\begin{array}{c}\text { Prior to PsA } \\
\text { Diagnosis }\end{array}$ & $\begin{array}{c}\text { After PsA } \\
\text { Diagnosis }\end{array}$ \\
\hline Number of Pregnancies & 70 & 33 & 37 \\
Live Births & $47(67 \%)$ & $24(73 \%)$ & $23(62 \%)$ \\
Spontaneous Abortion & $15(21 \%)$ & $4(12 \%)$ & $11(30 \%)$ \\
Stillbirth & $1(1 \%)$ & $0(0 \%)$ & $1(3 \%)$ \\
Ectopic Pregnancies & $1(1 \%)$ & $1(3 \%)$ & $0(0 \%)$ \\
Elective Termination & $6(9 \%)$ & $4(12 \%)$ & $2(5 \%)$ \\
Preterm Birth & $16 / 47(34 \%)$ & $5 / 24(21 \%)$ & $11 / 23(49 \%)$ \\
Preeclampsia & $11 / 46(24 \%)$ & $5 / 23(22 \%)$ & $8 / 23(35 \%)$ \\
Abnormal Infant & $1 / 47(2 \%)$ & $2 / 24(8 \%)$ & $2 / 25 *(8 \%)$ \\
Adverse Pregnancy Outcome & $33(47 \%)$ & $10(30 \%)$ & $23(62 \%)$ \\
\hline
\end{tabular}

*two twin pregnancies 